\title{
Disability and COVID-19: improving legal and policy responses through grassroots disability ethics
}

\author{
Ivanka Antova ${ }^{1}$ \\ Research Officer, Human Rights Consortium, Belfast \\ Correspondence email: ivanka.antova@gmail.com
}

\begin{abstract}
The emergency legal and policy responses to COVID-19 attempt to avoid discrimination against disabled people. But they do not address deeper ableist and disableist narratives and practices embedded in emergency health policy. Adopting a disability ethics approach to the guidelines that emerged during the COVID-19 pandemic shows that they rest on dubious ethical grounds. However, emergency legal and policy responses to COVID-19 can be improved by adopting an approach based on disability ethics principles that emerge from grassroots level.
\end{abstract}

Key words: disability; COVID-19; health policy; disableism; ableism; disability ethics.

\section{INTRODUCTION}

$A$ s national health systems across the world scrambled to address Athe strain that the COVID-19 pandemic was expected to place on their services, especially on intensive care units (ICUs), a myriad of guidelines emerged, aiming to help medical professionals to make difficult decisions about fair and equitable distribution of scarce healthcare resources. In the United Kingdom (UK), two such key instruments are the National Institute for Health and Care Excellence (NICE) rapid COVID-19 guidelines on critical care ${ }^{2}$ and the British Medical Association (BMA) 'COVID-19: ethical issues' guidance. ${ }^{3}$ Both guidelines state explicitly that direct discrimination against protected categories of patients, such as elderly patients and disabled patients, is illegal, unethical and should be avoided.

1 The support of the ESRC Health Governance After Brexit project, ES/S00730X/1, is gratefully acknowledged. In particular, Professor Tamara Hervey's generous help with the structure of this article is gratefully acknowledged and appreciated.

2 NICE, 'COVID-19 rapid guidelines: critical care in adults' (NICE, 20 March 2020).

3 BMA, 'COVID-19: ethical issues' (BMA, 7 September 2020). 
Yet, because they permit 'proportionate means for achieving a legitimate aim' and recognise a commitment to saving as many lives as possible as a 'legitimate aim', ${ }^{4}$ the guidelines have the effect of leaving space for indirect discrimination against disabled people. As a result, the ethical guidelines have not enjoyed universal acceptance, with the disability community in particular reacting with anger to what they perceived to be 'terrifying and discriminating' guidelines. ${ }^{5}$ These concerns remained even after the NICE guidelines were amended, in response to the threat of judicial review, ${ }^{6}$ to provide that direct discrimination on the basis of disability is inconsistent with the legal duty of equal treatment of all patients, and that medical professionals should conduct an individual assessment of disabled patients, rather than using a 'frailty assessment method'. ${ }^{7}$

The anger, distrust and fear of some in the disability community may seem unfounded and misplaced. After all, the legal principles of equality and non-discrimination apply irrespective of the COVID-19 pandemic, and disabled people can rely on those principles in this time as at all times. Protection from both direct and indirect discrimination is guaranteed by the provisions of the Equality Act 2010 and by the United Nations (UN) Convention on the Rights of People with Disabilities (UNCRPD) which the UK has ratified. ${ }^{8}$ This article challenges this perspective. Using 'grassroots disability ethics' (GDE), this article shows how ethical guidelines like the NICE and BMA guidelines embed deeper problems than those that can be resolved by a liberal equality perspective, even including indirect discrimination. GDE is understood in this article as conceptualisations and formulations of an ethical approach to emergency triage and the distribution of limited resources during the pandemic that are produced by disabled people themselves and by their organisations. GDE principles are informed by lived experiences of disability and are positioned here within the broader concept of disability inclusivity in

$4 \quad$ Ibid 7.

5 John Ping, "Coronavirus: anger over "terrifying and discriminating” intensive care guidelines' (Disability News Service, 26 March 2020).

6 The proposed judicial review, arguing that the 'frailty' assessment method in the guidelines was an unlawful limitation on the chances of a disabled person being admitted to an ICU, was brought on the grounds of unlawful discrimination in access to critical care, quoting arts 2, 3, 8 and 14 of the European Convention on Human Rights and ss 19 and 29 of the Equality Act 2010. See Local Government Lawyer, 'NICE amends Covid-19 critical care guideline after judicial review threat' (LGL, 1 April 2020).

7 NICE, 'NICE updates rapid COVID-19 guideline on critical care' (NICE, 25 March 2020).

8 Equality Act 2010, art 13 (direct discrimination) and art 19 (indirect discrimination). UNCRPD, art 5 (equality and non-discrimination). 
health policy. GDE principles embody a human rights-based approach to public health and health services, on account of explicitly referring to the human rights of disabled people. ${ }^{9}$ The article then demonstrates how the principles of GDE can be harnessed for better law- and policymaking. Thus, the article develops a rationale for both critiquing and improving current ethical guidelines.

The article proceeds as follows. After a brief discussion of the broader contexts, a conceptual framework for GDE is presented. Next, the detail of the guidelines is set out. While not formally law, guidelines like these have a quasi-legal status, in that, for instance, failure to adhere to them may result in disciplinary action or a tortious claim for damages should harm to a patient ensue. The main body of the article falls into two sections. First, it analyses the guidelines using the GDE framework, explaining their deficiencies from that perspective. Second, it shows how GDE principles may provide an alternative foundation for more inclusive healthcare decision-making, in the context not only of the UK's guidelines, but also similar guidelines elsewhere, and not only of COVID-19, but also of other health emergencies and situations of scarcity in healthcare resources.

\section{CONTEXTS: THE COVID-19 PANDEMIC AND DISABILITY}

Despite the popular opinion that COVID-19 is an equalising experience that affects everyone in the same way, 'we are not all equally in this together'. 10 Disabled people are disproportionately negatively affected by the global pandemic. At international level, a Global Monitoring Report, Disability Rights during the Pandemic, produced by a consortium of disability rights organisations, outlines the 'catastrophic' impact of the COVID-19 pandemic on persons with disabilities. The report describes the overwhelming failures of states to take sufficient measures when responding to the pandemic to protect the rights of persons with disabilities. ${ }^{11}$ The UN and the World Health Organization (WHO) have warned that disabled people are more at risk of contracting the virus and that some of the practical measures to stop the spread of the virus may not be possible for disabled people

9 Amanda Roberts et al, 'Treat me right, treat me equal: using national policy and legislation to create positive changes in local health services for people with intellectual disabilities' (2012) 26 Journal of Applied Research in Intellectual Disabilities 14-25, 16.

10 Katherine Hall et al, 'Ethics and equity in the time of coronavirus' (2020) 12(2) Journal of Primary Health Care 102.

11 Ciara Brennan et al, Disability Rights during the Pandemic: A Global Report on Findings of the COVID-19 Disability Rights Monitor (Global Monitoring Disability Report, 27 October 2020). 
to deploy. ${ }^{12}$ In addition, experiences of disabled people during the pandemic suggest that discrimination in critical triage is not a worstcase scenario for disabled people around the world, but a lived reality for many. ${ }^{13}$

At European level, the European Union(EU) Agency for Fundamental Rights' report, COVID-19 Pandemic in the EU, argues that the challenges that disabled people continue to face in their everyday life could even amount to discrimination in the context of the pandemic. ${ }^{14}$ For example, complex visiting guidelines or disproportionately implemented restrictions lead to greater stress and loneliness for disabled people. 15

More broadly, the impact of the pandemic on disabled people, and the discrimination that stems from it, should be seen in the context of historical barriers to healthcare and social care that disabled people have faced and continue to face. ${ }^{16}$ These barriers can be physical and social (such as inaccessible buildings and inaccessible transport), communications barriers (such as lack of assistive technology), or barriers emerging from stigma and discrimination at both individual and institutional level. ${ }^{17}$ Research on inequalities in health and social care reveals that many disabled people are discriminated against in relation to healthcare and that, despite some improvements of law and policy in the area, more progress must be made to ensure equal access to health and social care. ${ }^{18}$

In the UK, the disability community has expressed grave concerns about the emergency legal and policy response to the pandemic and the way that it encroaches on established disability rights. The UK pandemic response has been described as not thought-through, not

12 UN News, 'Preventing discrimination against people with disabilities in COVID-19 response' (UN News, 19 March 2020) .

13 Brennan et al (n 11) 43.

14 EU Agency For Fundamental Rights, COVID-19 Pandemic in the EU: Bulletin 4 (Publications Office of the EU, July 2020).

15 Ibid.

16 Ruel Serrano, 'Working to remove barriers to health care for people with disabilities' (WHO, 10 December 2012).

17 UN, Report on the World Situation 2018, 'Persons with disabilities: breaking down barriers' (UN Publications, 22 July 2018) ch 5.

18 See Afia Ali et al, 'Discrimination and other barriers to accessing healthcare: perspectives of patients with mild and moderate intellectual disabilities' (2013) 8(8) PLOS One; Heather de Vries McClintock et al, 'Health experiences and perceptions among people with and without disabilities' (2016) 9 (1) Disability Health Journal 74; Michael Stilman et al, 'Healthcare utilization and associated barriers experienced by wheelchair users: a pilot study' (2017) 10(4) Disability and Health Journal 502; Dora Raymarker et al, 'Barriers to healthcare: instrument development and comparison between autistic adults and adults with or without other disabilities' (2017) 21(8) Autism 972. 
proportionate and not protecting everyone. ${ }^{19}$ The Coronavirus Act 2020,20 the overarching legal response to the pandemic, is deeply problematic from a disability perspective, in particular because it removes the statutory duty on local authorities to provide social care services during the pandemic. ${ }^{21}$ Writing in 2013, the prominent disability scholar and activist Mike Oliver can now be seen as prophetic about the way in which the Coronavirus Act 2020, as a response to COVID-19, has changed disability rights:

Our differences are being used to slash our services as our needs are now being assessed as being moderate, substantial or critical and many local authorities are now only providing services to those whose needs are critical. 22

These are the contexts in which guidelines for medical professional practice in the context of COVID-19 were developed.

\section{GRASSROOTS DISABILITY ETHICS}

The historic barriers to healthcare outlined above, as well as the challenges brought by the COVID-19 pandemic, have strengthened the call for a disability-inclusive approach to the ongoing public health crisis. GDE principles for an ethical distribution of limited resources fit within the broader concept of a disability-inclusive approach to health and health policy. A disability-inclusive approach is understood as 'mainstreaming disability in all plans and efforts', as well as 'adopting targeted measures' that meet specific requirements, since general responses to the pandemic might not respond effectively to the particular needs of disabled people. ${ }^{23}$ Such an approach is inherently personcentred. It calls for the effective inclusion of disabled people as active participants in deciding how to meet their needs during the pandemic, alongside a core group of stakeholders, including family members and health professionals. ${ }^{24}$ Disability inclusivity in emergency responses is facilitated by challenging the 'morally reprehensible' deprioritising of disabled people during the pandemic with a strong focus on their

19 John Pring, ' Coronavirus: grave concern over impact of emergency Bill on rights' (Disability News Service, 19 March 2020).

20 Coronavirus Act 2020.

21 Ivanka Antova, 'Disability and COVID-19 in England: emergency policy and legal responses' (2020) 28(4) Medical Law Review 804-816.

22 Mike Oliver, 'The social model of disability: 30 years on' (2013) 28(7) Disability and Society 1024, 1026.

23 UN, Policy Brief: A Disability-inclusive Response to COVID-19 (2020) 8.

24 S Senjam, 'A persons-centered approach for prevention of COVID-19 disease and its impacts on persons with disabilities' (2021) 8 Frontiers in Public Health 3. 
human rights. ${ }^{25}$ As the pandemic lays bare the disproportionately negative impact of COVID-19 on disabled people, disability scholars have renewed the pre-pandemic call for radical changes to be made to the way disability policy and health policy are made by means of mainstreaming disability lived experiences. ${ }^{26}$

The inclusion of disabled people's voices and lived experiences in 'both direct and indirect measures in the fight against COVID-19' is a legal requirement.27 Article 4(3) of the UNCRPD requires states to 'closely consult and actively involve' disabled people and their representative organisations in the implementation of the Convention. In addition, article 33(3) requests states to ensure that disabled people participate fully in the monitoring of the implementation of the Convention. Disabled people and their organisations have been involved in the very creation of the UNCRPD through a 'unique' approach to treaty drafting that affords equal status to civil society members and state representatives, thus giving the UNCRPD an 'edge it would otherwise have lacked' had it not incorporated the lived experience of disability. ${ }^{28}$ The effective inclusion of disability in the creation of international and domestic human rights standards and health protocols has been seen as a key step towards 'reshaping present exclusionary practices and structures' that underpin to a large extent the disproportionately negative impact of the COVID-19 pandemic on disabled people. ${ }^{29}$

There are real practical merits in ensuring the effective participation of disabled people in the drafting of emergency responses to the pandemic. The lived experience of disability can inform practices that mitigate some of the negative impact of the pandemic by ensuring that emergency measures are 'appropriately tailored' for disabled

25 Hannah Kuper, Lena Morgon Banks, Tess Bright, Calum Davey and Tom Shakespeare, 'Disability-inclusive COVID-19 response: what it is, why it is important and what we can learn from the United Kingdom's response' [version 1; peer review: 2 approved] (2020) 5:79 Wellcome Open Research 3.

26 Laufey Löve, Rannveig Traustadótti, Gerard Quinn and James Rice, 'The inclusion of the lived experience of disability in policymaking' (2017) 6-33 Laws $1-16,2$.

27 Elena S Rotarou, Dikaios Sakellariou, Emily J Kakoullis and Narelle Warren, 'Disabled people in the time of COVID-19: identifying needs, promoting inclusivity' 11:03007 (2021) Journal of Global Health, 3

28 Löve et al (n 26) 3.

29 Ieva Eskyte, Anna Lawson, Maria Orchard and Elizabeth Andrews, 'Out on the streets - crisis, opportunity and disabled people in the era of Covid-19: reflections from the UK' (2020) 14 European Journal of Disability Research 329-336, 334. 
people. ${ }^{30}$ There have been some attempts to do this in the UK during the pandemic. Examples include the provision of information about COVID-19 and social-distancing measures in British Sign Language and Easy Read formats for those with intellectual impairments;31 or the development of guidance for carers of people with specific conditions, such as Alzheimer's. ${ }^{32}$ The effective inclusion of disabled people's voices will also be important for stepping into the 'new normal' of a post-pandemic world where the less-known long-term effects of COVID-19 are studied and addressed.

Although GDE principles for the ethical and non-discriminatory response to the pandemic fit within the broader frameworks of disability inclusivity, person-centred and human rights-based approaches to health policy, GDE principles are understood in this article as potentially further reaching. GDE calls for the elevation of grassroots disability narratives to the main source, or foundation, of the emergency legal and policy responses. In this sense, a more appropriate conceptual framework to highlight the potential of GDE to achieve the 'reform in both the process and direction of policymaking' that the COVID-19 pandemic necessitates is the concept of co-production. ${ }^{33}$

Co-production, or 'the involvement of patients, service users, and members of the public in the design and delivery of healthcare' is an example of a grassroots disability activist narrative that has been gradually mainstreamed in policymaking. ${ }^{34}$ Co-production goes beyond the call for effective inclusion of disabled people in health policy drafting and focuses on reversing the power disbalance within disability policy by placing disability lived experience as the leading expertise. A key element of GDE principles as co-production of emergency responses to COVID-19 (and to any future crisis) is the transformation of disabled people from passive recipients of legal and policy responses to active participants in 'collective organisational co-management and co-

30 Lieketseng Ned, Emma Louise McKinney, Vic McKinney and Leslie Swartz, 'COVID-19 pandemic and disability: essential considerations' (2020) 18(2) Social and Health Sciences 143.

31 MENCAP has produced an Easy Read summary of the government COVID-19 guidance from May 2021: The Coronavirus Rules from Monday 17th May.

32 The Alzheimer's Society has produced advice and guidance specifically for carers of people with dementia: 'Helping a person with dementia to keep safe and well during coronavirus'.

33 Peter Beresford, 'What are we clapping for? Sending people to die in social care: why the NHS did this and what needs to happen next?' in Peter Beresford et al (eds), COVID-19 and Co-production in Health and Social Care Research, Policy, and Practice Volume 1: The Challenges and Necessity of Co-production (Polity Press 2020) 94.

34 Nicola Gale, Patrick Brown and Manbinder Sidhu, 'Co-production in the epidemiological clinic: a decentred analysis of the tensions in community-based, client-facing risk work' (2018) 53 Social Policy Administration 203-218, 204. 
governance of health'. 35 This is crucially important for challenging definitions of disability as individual physiological failure, as worthlessness or as a societal burden. GDE principles thus have the capacity to radically disrupt 'wider social and cultural processes that disempower and exclude' in favour of the sharing of decision-making with the community that empowers individuals and protects human rights. ${ }^{36}$ During the pandemic, disabled people experience more than a higher risk of exposure to COVID-19, or lockdowns and socialdistancing measures incompatible with their lives. Disabled people experience emergency responses to the pandemic that allow for indirect discrimination and inherently disempower and exclude them. The coproduction of emergency legal and policy responses would allow for lived experience of disability to illuminate potentials for discrimination and produce truly effective protocols. Therefore, a GDE approach to the ethical guidelines that emerged during the pandemic is a key tool in both critiquing and improving legal and policy responses. The effectiveness of GDE in critiquing emergency guidelines is discussed next.

\section{THE GUIDELINES}

Both the NICE rapid COVID-19 guidelines on critical care ${ }^{37}$ and the BMA's 'COVID-19: Ethical Issues' guidance ${ }^{38}$ envisage difficult choices about prioritising patients having to be made by medical professionals only in a situation where the health system, or a particular hospital or ICU within it, is overwhelmed. In such a scenario, as the guidelines point out, however undesirable this might be, prioritisation of patients will become inevitable.

The BMA guidelines explicitly commit to each patient receiving the highest possible level of care during the pandemic. The BMA guidelines go on to balance two different, and competing, approaches to the distribution of limited resources. On the one hand, there is respect for the individual and the individual right to health. On the other hand, there is a utilitarian concern for the health of the population as a whole. If sufficient resources become unavailable, then utilitarianism must prevail, and the leading concern should be to minimise overall mortality and morbidity.

35 Andrew G H Thompson, 'Contextualising co-production and co-governance in the Scottish National Health Service' (2020) 5(1) Journal of Chinese Governance 48-67, 49.

36 Jane Booth, 'Empowering disadvantaged communities in the UK: missing the potential of co-production' (2019) 49 (2) Social Change 276-292, 282.

37 NICE (n 2).

38 BMA (n 3). 
Although doctors would find these decisions difficult, if there is radically reduced capacity to meet all serious health needs, it is both lawful and ethical for a doctor, following appropriate prioritisation policies, to refuse someone potentially life-saving treatment where someone else is expected to benefit more from the available treatment. 39

The guidelines acknowledge that, whilst this situation would necessitate difficult and possibly distressing decisions, age and disability on their own may not be the only factors to be taken in consideration. Decisions should be based on 'evidence and reason'. However, in some cases, age and disability may feature as part of such an evidenced and reasoned decision-making process.

What medical professionals should prioritise in these very challenging circumstances is a higher survival probability, and a consideration of which patients would be expected to benefit more from critical care. The most urgent cases, the least complex cases, and patients expected to live the longest as a result of receiving critical care should be prioritised. Patients with co-morbidities that would impact on their capacity to benefit from treatment should not be prioritised. Patients who have 'sufficient background illness' or those who are frail should not be prioritised. Long-term health conditions are seen as a reason not to prioritise, while the key factor for prioritisation should be the capacity to benefit quickly from treatment. 40

Although the guidelines recognise the key principle of reasonable adjustment as an important part of disabled people's equal access to health care, they envisage a scenario where this duty is affected by the pandemic. The guidelines' position is that reasonable adjustment should not 'trump' the utilitarian commitment to saving as many lives as possible. To this end, and only in this limited context, indirect discrimination, or unintentional discrimination against disabled patients because of their difference from other patients, would be ethical and lawful medical practice.

The NICE guidelines make similar arguments, but in a more broadbrush way. The NICE guidelines do not provide a detailed explanation of how decisions about whom to prioritise should be made in a situation where resources are insufficient. Instead, the NICE guidelines focus more heavily on the clinical factors that should be prioritised in decision-making.

The NICE guidelines state that, when making a decision about admitting a disabled patient to critical care, medical professionals should do two things. First, they should conduct an individual

39 Ibid 3.

40 Ibid. 
assessment of frailty. ${ }^{41}$ According to the NICE website, frailty is described as 'a loss of resilience that means people don't bounce back quickly after a physical or mental illness, an accident or other stressful event'.42 This definition is based on a British Geriatrics Society model for recognising and assessing frailty. ${ }^{43}$ Since the NICE guidelines are for admitting patients into ICUs, medical professionals would be able to make such assessments, and this suggests that the critical frailty score might still be used when deciding which patient should be prioritised in a situation of limited health resources.

The second thing medical professionals should do is follow the algorithm that the guidelines provide. According to the algorithm, if a patient is considered to be less frail, by using the individualised assessment described above, then admission into critical care is seen as appropriate. If the patient is deemed to be more frail, then a doctor must make an additional decision about admission to critical care as part of a holistic assessment. Although we have no detailed description of what a holistic assessment might mean, we can see from the guidelines that medical professionals should always consider comorbidities, underlying health conditions, pathologies and severity of acute illness when deciding whom to prioritise. ${ }^{44}$

\section{ANALYSIS}

The guidelines do not suggest that disabled patients should automatically be excluded from receiving critical care, nor do they make an explicit argument that disabled lives do not matter. But, although they proclaim that discrimination against disabled people is not permitted, the BMA and NICE guidelines nonetheless embody and articulate a highly problematic approach when seen from the point of view of GDE. This is the case for five main overlapping reasons:

- the approach of the guidelines to the balance between utility and equality;

- the construction of disability as abnormality;

- disability as representing low quality of life or health;

- a concept of the 'ideal patient'; and

41 NICE (n 2) (my emphasis). Note that the algorithm states that 'any patient aged under 65, or patient of any age with stable long-term disabilities (for example, cerebral palsy), learning disabilities or autism: do an individualised assessment of frailty. Do not use CFS score.'

42 NICE, 'Improving care and support for people with frailty: how NICE can support local priorities'.

43 Jill Turner, 'Recognising frailty: good practice guide' (British Geriatrics Society, 11 June 2014).

44 NICE (n 2). 
- the way the guidelines construct a disableist response to the COVID-19 pandemic from an ableist perspective.

Each is now discussed in turn.

\section{The utility/equality balance}

In the context of a global pandemic, or other health emergency, the necessity to prioritise limited resources inherently dictates that judgements about the value of lives will have to be made. To this end, the guidelines embody what has been described as an 'unstable compromise'45 between competing ethical approaches, namely utilitarianism and egalitarianism. The scenario where the overall health of the population is seen as competing with the health of individuals is a fertile ground for negative conceptions of disability as a 'product of a damaged body or mind' 46 to underpin decisions about who should be saved and who should not be.

The guidelines state that utilitarian concerns override commitment to prioritising each patient, regardless of how their individual health might be perceived or valued. When developing an ethical reasoning or practice for distributing limited resources, the guidelines adopt an approach based on orienting activity toward a utilitarian good. In effect, this utilitarian good amounts to a devaluing of disabled lives, as less worthy of public investment. 47 Consistently with public health ethics, the utilitarian approach typically prioritises young and healthy people. 48 The BMA guidelines in particular make an explicit call for the overall morbidity and mortality being minimised, by allowing for disability to feature as a decision-making factor when choosing the patients in whom limited resources should be invested.

Such a utilitarian approach prioritises 'normal' and 'healthy' lives, and the overall health of a nation. A categorical exclusion, understood as a manifestation of the utilitarian principle of maximising population outcomes, would exclude patients with certain co-morbidities (for instance, severe cognitive impairment) as a priority for critical care. ${ }^{49}$

45 Julian Savulescu, James Cameron and Dominic Wilkinson, 'Equality or utility? Ethics and law of rationing ventilators' (2020) 125(1) British Journal of Anaesthesia 10.

46 Dan Goodley and Katherine Runswick-Cole, ‘The violence of disablism' (2011) 33(4) Sociology of Health and Illness 602, 603.

47 Shane Neilson, 'Why I won't see you on the barricades' (2020) 66 Canadian Family Physician 448, 450.

48 Jerome Singh and Keymanthri Moodley, 'Critical care triaging in the shadow of COVID-19: ethics considerations' (2020) 110(5) South African Medical Journal $355,355$.

49 Douglas White and Bernard Lo, 'A framework for rationing ventilators and critical care beds during the COVID-19 pandemic' (2020) 323(18) Journal of the American Medical Association 1773, 1773. 
It would be more ethical to prioritise a non-disabled person because they would be understood as able to make a better contribution to the overall health of society, after recovery. But this population-focused utilitarian approach runs the risk of turning 'critical care into a life raft: the vulnerable are thrown overboard to keep the ship afloat'.50

An alternative, less restrictive, non-categorical utilitarian approach would focus on universal eligibility for critical care, but would see a prioritisation based on who would be 'most likely to benefit'. The people most likely to benefit are seen as those who would survive to hospital discharge if given the treatment. For example, it would be ethical to prioritise those with more years left to live, whether disabled or not. Or it would be ethical to prioritise younger patients, whether disabled or not, in order to give everyone an equal chance of going through all life stages (the life-cycle principle). ${ }^{51} \mathrm{~A}$ GDE approach to the guidelines reveals that even this utilitarian approach runs the risk of perceiving disabled people as less likely to benefit from treatment because of how disability is understood, as opposed to an able-bodied or cognitively able 'norm'.

\section{Disability as abnormality}

When disability is seen as failure or abnormality, the life of a disabled patient is unlikely to be valued as much as a life that is considered 'normal' and a part of the health of a 'normal' society. Grassroots disability narratives have long challenged the portrayal of disability as abnormality and as an individual tragedy, rather than the end result of structural barriers and inequalities. From a GDE perspective, the COVID-19 ethical guidelines can be understood as a continuation of the long-standing discussion within disability studies about the prevalence of medical conceptions of disability, as opposed to conceptions of disability that aim to distance disability from biological determinism and functionalism (broadly speaking the social model of disability).

The medical model of disability, also referred to as the individual or 'personal tragedy' model of disability, is an early theory of disability that emerged from the medical profession, with the medical knowledge on the functions or performances of the body constructing disability

50 Andrew Peterson, Emily Largent and Jason Karlawish, 'Ethics of reallocating ventilators in the Covid-19 pandemic' (2020) 369 British Medical Journal 1, 1.

51 White and Lo (n 49). 
as a failed performance or abnormally functioning body or mind. 52 Goodley describes what is understood here as a medical model as the dominance of functionalism as a social theory, which sees disability as the product of a damaged body or mind, thus 'functionalism underpins ableism: the social, cultural and political conditions of contemporary life that emphasise ability and denigrate disability'. ${ }^{53}$ The medical model works through individualisation of disability. ${ }^{54}$ The human body is seen as a 'universe' in itself and the 'problems' of this body are limited by the physical contours of the body, not to be equated with problems that a population or a group of people might experience collectively. Therefore, the medical model of disability is a highly divisive way of thinking: "within the purview of the medical establishment, to keep it a personal matter and "treat" the condition and the person with the condition rather than "treating" the social processes and policies that constrict disabled people's lives'. 55 The COVID-19 pandemic presents significant challenges to disabled people that necessitate a deeper understanding of how disabled lives should be protected than the medical model affords.

By contrast, the social model of disability, which has become the normative analytical framework for disability studies, separates impairment from disability and places disability as the end result of the barriers that society creates. ${ }^{56}$ The social model emerged as a framework to make sense of disability in 1976 in the work of the Union of the Physically Impaired Against Segregation (UPIAS), a group of disabled activists and socialists. Mike Oliver further elaborated the

52 Marno Retief and Rantoa Letšosa, 'Models of disability: a brief overview' (2018) 74(1) HTS Teologiese Studies/Theological Studies a4738, 3. See also Andrew J Hogan, 'Social and medical models of disability and mental health: evolution and renewal' (2019) 191(1) Canadian Medical Association Journal E16-E18; Jonathan M Levitt, 'Developing a model of disability that focuses on the actions of disabled people' (2017) 32(5) Disability and Society 735-747; and Stephen Bunbury, 'Unconscious bias and the medical model: how the social model may hold the key to transformative thinking about disability discrimination ' (2019) 19(1) International Journal of Discrimination and the Law 26-47.

53 Goodley and Runswick-Cole (n 46) 603.

54 Joel Michael Reynolds, "I'd rather be dead than disabled" - the ableist conflation and the meanings of disability' (2017) 17(3) Review of Communication 149-163, 151.

55 Simi Linton, Claiming Disability: Knowledges and Identity (New York University Press 1998) 4.

56 Jonathan Levitt, 'Exploring how the social model of disability can be reinvigorated: in response to Mike Oliver' (2017) 32(4) Disability and Society 589. 
social model in $1983^{57}$ and 1990,58 later describing it as nothing more than 'a tool to improve people's lives'. 59

In the UK, the social model of disability has indeed been a highly effective tool for disability activism and emancipatory disability narratives (within which GDE can be placed), despite critiques of the social model and many of its limitations having been discussed at length. 60 Perhaps most importantly, critical disability studies scholars looking to go beyond the social model have argued that 'bodies are not simply born, but made'.61 The strict separation of impairment from disability could leave the disabled body (or mind) open to theoretical interventions and definitions from a medical perspective alone, rendering disability a personal tragedy or failure, rather than an experience affecting many. ${ }^{62}$ A GDE approach would instead prioritise disability-led, inclusive and human rights-centred definitions of disability, in line with the social model of disability.

The BMA and NICE guidelines can be seen as emergency responses that have inherited the medicalisation of disability, which dominates the medical profession. By relying heavily on utilitarian principles to justify indirect discrimination against disabled patients, the ethical guidelines in effect prioritise 'normality' when decisions about who should receive scarce healthcare resources are made. Thus, the guidelines reinforce the notion that 'abnormality' can and should be excluded if resources are limited. As such they are an embodiment of the medical model of disability that many disabled people see as undermining the validity of their existence.

The WHO requires states to 'ensure that decisions on the allocation of scarce resources (eg ventilators) are not based on pre-existing impairments, high support needs, quality of life assessments, or medical bias against people with disability'.63 But guidelines like the BMA and NICE guidelines do not provide the necessary clarity 64 to medical professionals, especially where they lack knowledge and have

57 Mike Oliver, Social Work with Disabled People (Macmillan 1983).

58 Mike Oliver, The Politics of Disablement (Macmillan 1990).

59 Oliver (n 22) 1025.

60 Janine Owens, 'Exploring the critiques of the social model of disability: the transformative possibility of Arendt's notion of power' (2014) 37(3) Sociology of Health and Illness 385.

61 Elizabeth Donaldson, 'The corpus of the madwoman: toward a feminist disability studies theory of embodiment and mental illness' (2002) 14(3) Feminist Disability Studies 99, 112.

62 Ibid.

63 WHO, Disability Considerations during the COVID-19 Outbreak (WHO 2020).

64 Richard Huxtable, 'Bin it or pin it? Which professional ethical guidance on managing COVID-19 should I follow?’ (2020) 21(1) BMC Medical Ethics 1, 9. 
insufficient training in the needs and rights of disabled people. 65 In those circumstances, where medical professionals conduct the individual assessment required by the guidelines when deciding whom to prioritise for limited resources during the pandemic, such an assessment would involve an individual disabled person being evaluated and labelled through a process which separates that disabled person from mainstream society, education, work or social interaction. The separation arises because a disabled person is seen as deviating from an implicit dominant norm, and their difference is not valued.66

\section{Disability as low quality of life or health}

In a similar way, the guidelines embody the idea that disability is associated with a low quality of life, or health, when compared to an able 'norm'. Within the medical model, disability is understood as inherently negative, something to be endured, which should be cured or even eliminated, if possible.67 A GDE perspective would offer an understanding of life with a disability as something that might be experienced, or even enjoyed, as a normal part of the life of an individual. When disabled people enter the medical field, they encounter difficulties or barriers because quotidian experiences for them (such as the use of feeding tubes or respirators) become indicators of an unacceptably low quality of life. ${ }^{68}$ Including quality of life as a factor 'risks incorporating concerning value judgments that will systemically disadvantage people with disabilities and chronic health conditions and reduce the likelihood that they will receive medically indicated care'. 69 The perception of disability as an inevitable prognosis for bad quality of life post-critical care, or as a negative prognosis in terms of a fast recovery, allows for disabled patients to be deprioritised for access to a ventilator, even if they need it more than a non-disabled person presenting with the same disease. 70

As the guidelines are applied by medical professionals, disabled people's impairments, or underlying health conditions that may be the reason for their disability, will be seen as a medically relevant ground for exclusion from prioritisation of resources. This is the case

65 Maya Sabatello et al, 'People with disabilities in COVID-19: fixing our priorities' (2020) 20(7) American Journal of Bioethics 187, 187.

66 Owens (n 60).

67 Fiona Campbell, Contours of Ableism: The Production of Disability and Abledness (Palgrave MacMillan 2009) 5.

68 Heidi Jenz, 'Ableism: the undiagnosed malady afflicting medicine' (2019) 191 Canadian Medical Association Journal E478, E479.

69 Ari Ne'eman, 'When it comes to rationing, disability rights law prohibits more than prejudice' (The Hastings Centre, 10 April 2020) 2 .

70 Gerard Goggin and Katie Ellis, 'Disability, communication, and life itself in the COVID-19 pandemic’ (2020) 29(2) Health Sociology Review 168, 171. 
even though disabled patients are seeking ICU admission because of COVID-19 and not because of a stable or a long-term health condition that they would otherwise manage. Disability, when understood only as reduced capacity to function 'normally', may be seen as inherent frailty, or as incapacity to be 'healthy' despite access to critical care.

The merit of applying a geriatric model of frailty assessment to disabled patients is highly questionable, since old age and disability may overlap in certain cases, but are certainly not the same thing. Frailty is assessed by various means, for example looking into the speed of walking, the strength of a grip, any increased challenges in getting out of bed or going to the toilet. For some disabled patients with particular health conditions or impairments these challenges may be an everyday reality, not necessarily a signal of increased frailty that may be seen as a reason not to be prioritised for critical care during a pandemic. Even the British Geriatrics Society model allows for the use of the critical frailty score, only after a comprehensive individual clinical assessment.

This concern about a frailty model lies at the heart of the successful challenge to the original NICE guidelines, which were amended precisely because they equated disability with frailty and frail patients were to be excluded from receiving critical care in favour of less frail, or non-disabled patients. The now amended NICE guidelines call on medical professionals to recognise the limitations of assessing disability as frailty and insist on an individualised assessment to be carried out instead. But it is precisely during this individualised assessment that the perception of disability as low quality life or health enters the decision-making process. Indirect discrimination against disabled people takes place when disabled lives and experiences are measured against an unattainable 'ideal' notion of health and humanity that distinguishes between disabled people and non-disabled people and leaves the former in a disadvantageous position. The ethical guidelines require attention to quality of life post-treatment. A GDE approach to the guidelines reveals that, where disabled lives are seen as lower quality and disabled people perceived as having a lower quality of health, the guidelines steer resourcing decisions in a way that discriminates against disabled people.

\section{The 'ideal patient'}

The NICE and BMA guidelines suggest that patients without underlying health conditions and co-morbidities, with a better ability to survive, with a better chance of benefiting from treatment and, perhaps most importantly, with less complexity to their health circumstances, would be ideal for prioritisation during the pandemic. In other words, the guidelines prioritise those who are seen as healthier already, 
or those patients who are seen to be the closest to the unattainable health performance that constructs disability as lacking. From a GDE perspective, this is problematic. It articulates a normative notion of a rational, independent, autonomous subject, embedded in the notion of an ideal human patient. Such an 'ideal patient' is often evoked in policy making, ${ }^{71}$ and COVID-19 guidelines are no exception. The guidelines lean heavily towards protecting this normative construction that leaves disabled patients, who inevitably challenge the hegemony of the 'ideal patient', in a disadvantageous position.

\section{The pandemic constructed from an 'ableist' and 'disableist' perspective}

Making this point more broadly, law and policy processes that construct human bodies according to an 'ideal' also contribute to ways that pandemic responses, like the BMA and NICE guidelines, embody and articulate an approach that is highly problematic from the point of view of GDE.

The ideal patient described above, the one who should be prioritised for limited health resources during a pandemic, is an example of defining disability as the opposite of ideal or normal. From a critical disability perspective, defining disability is about destabilising a definition of disability that relies on normative idealised understandings of how the human body or mind should perform. To build this destabilising narrative, critical disability scholars have developed the concepts of 'ableism' and 'disableism' as the two sides of the same coin, mutually supporting and promoting each other. ${ }^{72}$ Goodley defines ableism as an ideal, not something to which anyone ever matches up. Disableism is the process of pressing normative ableism upon people: 'the oppressive practices of contemporary society that threaten to exclude, eradicate and neutralise those individuals, bodies, minds and community practices' that do not reach the unattainable ableist standard. ${ }^{73}$ These practices occur across social contexts, including in the medical field. From this perspective, two entirely distinct categories exist: disabled or able, ${ }^{74}$ the latter of which does not exist in absolute form, but as an imagined norm to which people can be compared. Ableist-normativity

71 Dan Goodley and Katherine Runswick-Cole, 'Becoming dishuman: thinking about the human through dis/ability' (2014) Discourse: Studies in the Cultural Politics of Education 2.

72 Dan Goodley, Dis/ability Studies: Theorising Disablism and Ableism (Routledge 2014) ix.

73 Ibid xi.

74 Campbell (n 67) 8. 
is constantly produced and maintained through such comparisons, ${ }^{75}$ ensuring that disableist discrimination takes place, by implicitly casting disabled people as comparatively 'less-than-human'. ${ }^{76}$

The COVID-19 ethical guidelines overtly favour those patients who are closer to the ableist normativity of the healthy individual, by marrying body performativity that challenges the notion of 'being healthy' with relevant medical factors that determine who should be prioritised for the limited health resources. The systemic nature of ableism and disableism is reproduced in the guidelines:

Governmental policies, laws, and rules ... are designed for the benefits of the privileged group, people without impairment or disability. Ableism is constructed on the basis of hierarchy where people without disability are on the top. 77

According to the guidelines, medical professionals should prioritise a higher survival probability, those expected to benefit more from treatment, the least complex cases, patients without co-morbidities or background illness, those most likely to recover, and those with capacity to recover quickly. These factors may seem perfectly relevant and objective to a medical professional, or to a lay person. The argument here is not that medical professionals would deliberately discriminate against disabled people. It is rather that medical professionals rely on an ableist definition of disability as a fixed or stable body or mind that simply does not perform as well as a non-disabled body or mind. In that context, the perception that medical intervention is less likely to 'fix' a disabled person's chances of recovery, even if critical care is administered, appears rational.

From a GDE perspective, however, when understood as incorporating the lived experience of the effects of processes of ableism/disableism, the guidelines fail to recognise or reflect the much more complex and fluid range of disability experiences. The medical profession is not exempt from producing ableist narratives and disableist practices under the disguise of medical knowledge or 'common sense'. '[A]bleism is that most insidious form of rhetoric that has become reified and so widely accepted as common sense that it denies its own rhetoricity-it "goes without saying".'78

75 Fiona Campbell, 'Refusing able(ness): a preliminary conversation about ableism' (2008) 11(3) Media and Culture 1.

76 Laura Sanmiquel-Molinero and Joan Pujol-Tarrés, 'Putting emotions to work: the role of affective disablism and ableism in the constitution of the dis/abled subject' (2020) 33(4) Disability and Society 602, 605.

77 Heeson Jun, Social Justice, Multicultural Counselling, and Practice: Beyond a Conventional Approach (Springer International 2018) 246.

78 James Cherney, 'The rhetoric of ableism' (2011) 31(3) Disability Studies Quarterly. 
Medical criteria that may be accepted as common sense, or, as the guidelines embody, the implicitly inevitable processes that doctors have to follow in the context of resource shortage, are not necessarily objective or value-free. Rather, they can be understood as an example of medical ableism exerting pressures during the pandemic that allow for disableism in the form of legal and ethical discrimination against disabled people to be justified within the guidelines. Critical care could be denied a disabled person, consistently with the guidelines, based on an ableist perception of the disabled person's quality of life or health applied during a triage process: a third party (medical professional) concludes that the disabled person's life has insufficient quality to be worth saving in comparison with non-disabled (or, rather, less disabled, as 'able' is an unattainable norm) others. ${ }^{79}$ What may be considered as 'common sense' or medical objectivity, from a GDE perspective is revealed as smuggling in judgements on quality of life. These judgements are particularly pernicious when 'health' is nebulously defined as 'wellbeing', in effect a synonym for quality of life. 80

Equally, consideration of long-term survival and short-term survival as a relevant factor is problematic from a grassroots disability perspective. Decisions, at least on allocation of treatment modalities and hospital beds, based on long-term or short-term survival have been seen as appropriate in the context of COVID-19.81 But these have the effect of discriminating against disabled people, who regularly outlive the prognosis ascribed by medical professionals, often by decades. A disability does not automatically indicate a poor prognosis for short or longer-term survival. 82

To summarise: from the point of view of GDE, the guidelines can be understood as constructing responses to the COVID-19 pandemic from an ableist perspective, which undervalues equal treatment of different bodies (or minds) in the name of a utilitarian approach to individual and societal health, 'well being' or quality of life that is constructed by reference to an 'ideal patient' who does not embody an 'abnormal' disability. Thus, the guidelines permit processes of decision-making that have the effect (even if not the intention) of discriminating against disabled people.

79 Joseph Stramondo, 'COVID-19 triage and disability: what NOT to do' (Bioethics Net, 30 March 2020).

80 Anthony Gavin, 'The poverty of bioethics: disability, medical austerity, and traumatic care' (Social Sciences and Humanities Open, 4 June 2020).

81 Naomi Laventhal et al, 'The ethics of creating a resource allocation strategy during the COVID-19 pandemic' (2020) 146(1) Pediatrics 4.

82 Disability Rights Education Defense Fund (DREDF), 'Applying HHS' guidance for states and health care providers on avoiding disability-based discrimination in treatment rationing' (Disability Rights Education and Defense Fund, 3 April 2020). 


\section{AN ALTERNATIVE APPROACH: GDE}

It is one thing to critique a law or policy from an external standpoint. It is quite another to offer an alternative approach. This article argues that GDE provides not only a standpoint for critique, as shown above, but also a basis for an alternative approach to healthcare decisionmaking in the context of COVID-19, and indeed in broader contexts, involving healthcare emergencies and/or scarcity of healthcare resources such as ICUs. GDE has potential to provoke positive change in three contexts: healthcare practice, healthcare policy and disability ethics more generally.

To illustrate this potential, let us first contrast the position of two doctors, from the UK and Canada, in terms of how they understand the decision-making required of them under ethical guidelines such as the BMA or NICE Guidelines.

Consider first the perspective of Dr Matt Morgan, a UK -based NHS doctor from Cardiff. Dr Morgan wrote an open letter from an ICU 'to those who are elderly, frail, vulnerable, or with serious underlying health conditions'.83 In this remarkable letter, Dr Morgan reassures these people that they have not been forgotten. But observe the way in which the role of the medical professional is described during the pandemic:

Our passion as an intensive care community is fixing problems that can be fixed. Yet we often meet patients like you who have problems that cannot simply be fixed ... As difficult as this is, we will be honest. We will continue to use all of the treatments that may work and may get you back to being you again. We will use oxygen, fluid into your veins, antibiotics, all of the things that may work. But we won't use the things that won't work. We won't use machines that can cause harm. We won't press on your chest should your heart stop beating. Because these things won't work. They won't get you back to being you. 84

To Dr Morgan, the point of doctors is to 'fix' patients. The challenge that disabled patients present is that they cannot be 'fixed'. In the context of a global pandemic and limited resources, this challenge becomes more acute. Not even powerful technology and advanced medication can fix the problem. The end strategy seems to be a nod towards 'do not resuscitate'. 85 Compassion, care, attention and understanding of disabled people is not denied here, quite the opposite. There is a nod to individual experience: 'you being you'. But there is a stronger sense of disableist inevitability in Dr Morgan's words that the responses to

83 Matt Morgan, 'Letter from ICU' (The BMJ Opinion, 12 March 2020).

84 Ibid (my emphasis).

85 John Pring, 'Coronavirus: activists' shock at intensive care doctor's resuscitation warning' (Disability News Service, 19 March 2020). 
the pandemic will be impacting negatively on disabled people and a resignation or even acceptance that this cannot be changed, or 'fixed'.

Now, by contrast, consider the perspective, of Dr Shane Neilson, a Canadian doctor and scholar, and a father of a disabled son. In his opinion piece ('Why I won't see you at the barricades'), Dr Neilson discusses the 'vexed' relationship between the medical profession and disability, one that has historically disadvantaged and discriminated against disabled people. Dr Neilson responds to the call of duty to the profession to intensify work efforts during the pandemic and make difficult decisions on prioritising resources (to go to the barricades) with the following:

In truth, I love to go to work, but not for you, not exactly; not for an abstract ideal; definitely not for emergency services vehicles sounding their klaxons in a fluid cordon around a building. I do it for me, because I like doing it, love it in fact. I do it because I like helping someone else; it makes me feel good. But the second my work becomes an activity oriented toward a utilitarian good, a recruited assent toward devaluing disabled lives, and a requirement I place myself at greater risk (and thereby my family, including my disabled son), I say no. 86

Dr Neilson, in contrast to Dr Morgan, acknowledges the inherent unfairness of the necessity to prioritise resources for patients who can be 'fixed'. Dr Neilson does not accept the disableist inevitability of the medical profession having to make these decisions with a compassionate confidence in their ethical soundness. In fact, he calls for action and resistance: 'When disabled lives are explicitly protected by a discipline that historically has preferentially extinguished them that's when I'll join you at the barricades.' 87

GDE principles are principles for the ethical, fair and just distribution of limited resources that disabled people produce themselves based on their lived experience, and hoped-for futures, 88 and expertise in navigating through the complexities of ableism, disableism and different models of disability described above. Far from being passive recipients of ethically questionable emergency responses to the global pandemic, the disability community has been active in its resistance to the brutality of utilitarianism, to the reductionism inherent in bioeconomic decision-making, and to the expressions of the value or worth of human lives these kinds of responses, including as embodied in the BMA and NICE guidelines, entail. 89

86 Neilson (n 47) 450.

87 Ibid 450.

88 Ibid 449.

89 Thomas Abrams and David Abbott, 'Disability, deadly discourse, and collectivity amid coronavirus (COVID-19)' (2020) 22(1) Scandinavian Journal of Disability Research 168. 
Perhaps the most valuable contribution GDE can make to the evolving subject of ethics during the COVID-19 pandemic is in recognising the importance and prioritising the inclusion of lived experience in legal and policy responses to this pandemic, as well as future public health crises. Guidelines for provision of healthcare during COVID-19 must be developed in collaboration with disabled people's organisations and representatives from human rights bodies. Disability ethics based on lived experience can be a valuable tool for overcoming ideological divides and ethical disagreements, especially those which are framed as in-principle zero-sum decisions. The lived experience has a transformative power in ethical contexts. Instead of talking about abstract or theoretical concepts, to be solved by logical consistent argument, the conversation becomes about a set of concrete problems to be solved with practical reform informed by real people's experiences. 90 The medical profession has historically excluded disability voices, experiences and deconstructions of normative concepts like ableism. The COVID-19 pandemic requires bolder action to make sure these voices are included, not silenced. ${ }^{91}$ Such bold action necessary to incorporate insights from disabled people's lived experience would require more effective inclusion policies and practices.

First, lived experience has the potential to inform healthcare practice and to help the medical profession to acknowledge, recognise and address the medical ableism that is often presented as scientific objectivity, but risks leaving both patients and practitioners exposed to the harsh consequences of decisions being based on questionable ethical grounds. COVID-19 presents an opportunity to provide all healthcare staff with rapid training on the rights of disabled people. 92 That training should embrace understandings of disability informed by lived experience and should distance itself from categories of 'normal' and 'abnormal' as abstract pathologies. 93 Understanding and awareness of disability ethics can help medical professionals, who have limited knowledge or appreciation of disability experience, when

90 Joseph Stramondo, 'Doing ethics from experience: pragmatic suggestions for a feminist disability advocate's response to prenatal diagnosis' (2011) 4(2) International Journal of Feminist Approaches to Bioethics 48, 71.

91 Emily Lund and Kara Ayers, 'Raising awareness of disabled lives and health care rationing during the COVID-19 pandemic' (2020) 12(S1) American Psychological Association S210, S211.

92 Richard Armitage and Laura Nellums, 'The COVID-19 response must be disability inclusive' (2020) 5(5) Lancet Public Health.

93 Shane Neilson, 'Ableism in the medical profession' (2020) 192(15) Canadian Medical Association Journal E411, E412. 
making decisions about how disabled lives are to be valued in a triage situation, 94 on the basis of ethical guidelines.

Second, lived experience can also have a positive effect on health policymaking during the pandemic. For example, one of the policy responses to the pandemic in Northern Ireland has been the proposal to create a Mental Health Champion to represent the views and experiences of patients with a mental health disability and who can hold decisionmakers accountable in terms of responding to the ever-changing pandemic landscape. In a statement following the announcement from the Northern Irish Department of Health, Disability Action Northern Ireland (DANI) urged (as a minimum) that criteria for appointment should include that the applicant has personal lived experience of mental ill health.95

GDE principles have the capacity to create alternatives to the ethical guidelines. For example, in a recent statement to the BMA following the publication of the BMA ethical guidelines, DANI produced the following guiding principles for ethical guidelines:

We believe it is critically important healthcare professionals have guidance which includes and accurately reflects disabled people as citizens with fundamental rights (like all others) in the difficult times ahead.

We also believe it is critical that we all have the medical equipment and resources needed.

We call on the BMA to now reach out and meaningfully engage with Disabled People's Organisations. Participation is central to a rightsbased approach to health.

We are all in this together. 96

On the basis of these kinds of principles, guidelines for healthcare decision-making in the context of pandemic-induced scarcity could be altered to express the following. As far as possible, decisions about allocation of scarce healthcare resources should be made in advance and actively include the public (most importantly disabled people themselves). $97 \mathrm{GDE}$ calls for the co-production of guidelines where disability lived experience is an equal in value expertise upon which they

94 Satendra Singh, 'Disability ethics in the coronavirus crisis' (2020) 9(2) Journal of Family Medical Primary Care 167, 171.

95 Disability Action NI, 'Open letter to Minister Swann et al' (DANI, 23 April 2020).

96 Disability Action NI, 'Disability Action deeply concerned by recent BMA Guidance "COVID-19: ethical issues”' (DANI, 2 April 2020).

97 Lawrence Gostin, Eric Friedman and Sarah Wetter, 'Responding to Covid-19: how to navigate a public health emergency legally and ethically' (2020) 50(2) Hastings Center Report 8, 9. 
are developed. Guidelines must be transparent and based on clearly explained rationales that are compatible with a person-centred and a human rights-based approach to health. ${ }^{98}$ There must be a thorough, individualised review of each patient, 99 grounded in scientific evidence related to transmission of the virus, morbidity and mortality. ${ }^{100}$ Such review must avoid explicit or implicit assumptions about the value or quality of life of a patient, based on aspects of their ability unrelated to COVID-19, so that the individual chance of a disabled person with COVID-19 to benefit from treatment is not influenced by how disabled lives are valued by society. Access to treatment decisions should not consider whether someone has a disability, or a proxy for a disability such as 'frailty'. Instead, they should focus on the patient's prospects of benefiting from treatment. ${ }^{101}$ Where disabled people have existing health conditions or impairments that are unrelated to their chance of benefiting from treatment, those pre-existing conditions must not play any part in decision-making regarding a disabled person's equal right to access such treatment. ICU triage protocols should focus on identifying the patients who are most likely to die without a ventilator, but are the most likely to survive with one. They should do so using the best available clinical survivability scores, applied on an individual basis, not using broad categorical exclusions. ${ }^{102}$ Going further, medical professionals should take decisions based not on an abstract 'norm' of able-bodied (or able of mind), but cognisant that every body (and mind) is different.

Third, and more ambitiously, GDE principles based on lived experience are also a vital part of the developing field of disability ethics. As such, GDE can have the function of transforming practice, through creative and emancipatory disruption of established ways of behaving, established ethical considerations and principles. In the same way in which disability disrupts and challenges ableist normativity, disability ethics can challenge the dubious theoretical grounds, or the uncomfortable compromise between competing ethical frameworks, by ushering in the power of lived experience.

\footnotetext{
98 Ibid 9.

99 DREDF (n 82).

100 Gostin et al (n 97) 9.

101 Michelle Mello et al, 'Respecting disability rights - toward improved crisis standards of care' (2020) 383 New England Journal of Medicine e26.

102 Mildred Solomon et al, 'Covid-19 crisis triage - optimizing health outcomes and disability rights' (2020) 383 New England Journal of Medicine e27.
} 


\section{CONCLUSION}

Grassroots disability ethics principles are those for the ethical and fair distribution of resources and organisation of society that emerge from disabled people themselves. This article has shown that GDE can be used to help illuminate serious problems with COVID-19 guidelines, such as the NICE rapid COVID-19 guidelines on critical care ${ }^{103}$ and the BMA 'COVID-19: ethical issues'.104 Although these guidelines, like many others across the globe, do not overtly discriminate on grounds of disability, they do raise the possibility of indirect discrimination against disabled people, potentially involving the denial of life-saving treatment. More profoundly, the guidelines embody a disableist approach that non-discrimination law alone cannot address. This deeper problem lies with how disabled lives are understood, valued and consequently protected during the pandemic.

More broadly, and perhaps most poignantly, the NICE and BMA ethical guidelines, despite committing to avoiding direct discrimination, may be failing to achieve what they set out to do. The main purpose of both guidelines is to bring clarity and reassurance to both NHS staff who are tasked with making difficult decisions and to disabled patients who have to endure the consequences of these decisions. In their current form, the guidelines provide no such clarity. Instead, they encourage the formation of two opposing and incompatible 'camps': medical professionals versus disabled people, leaving very little space for sharing ideas, experiences and solidarity. Whilst more research is needed into the experiences with regard to the guidelines of both medical professionals and disabled patients during the pandemic, it is nonetheless safe to argue that GDE principles of including disability voices in the legal and policy responses to the COVID-19 pandemic would offer a stronger ethical foundation that brings clarity and reassurance to everyone.

Going further, GDE principles can be used as a foundation upon which to build a disability-inclusive and disability-led response not only to the current COVID-19 crisis, but to other contexts where healthcare resources become scarce. Disability-led narratives on what constitutes ethical, fair and just prioritisation of patients during the pandemic are missing from the guidelines. Yet, these disability-led narratives would offer the key improvement to the guidelines, as they would prevent the historic devaluation of disability to allow for indirect discrimination against disabled patients to be seen as an acceptable means to achieve a legitimate aim. Disability voices and experiences must be included in all policy and legal responses to the current pandemic, as well as 
any future health crisis. Including disability voices and experiences in the construction of legal and policy responses to health crises has the potential to disrupt medicalised 'common sense' on disability in the health field and encourage the cross-pollination of practice with discussions from critical disability studies, disability rights and ethics. 